Military Technical College

Kobry El-Kobbah,

Cairo, Egypt

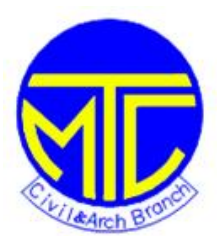

$9^{\text {th }}$ International Conference on Civil and Architecture

Engineering

ICCAE-9-2012

\title{
USE OF WASTE POLYESTER FIBERS TO ENHANCE RUTTING RESISTANCE OF ASPHALT CONCRETE MIXTURES
}

\author{
A. El-Desouky*, A. Abbas**, L. Radwan***, O. Moursi****
}

\begin{abstract}
The vast amount of waste materials such as polyester waste fibers accumulating throughout the world is creating costly disposal problem. The use of these materials was proved to be economical, environmentally an d effective in increasing the performance properties of the asphalt mixture in new years. The main objective of this research was to determine whether homogeneously dispersed waste polyester fibers improve Marshall stability and rutting resistance of asphalt concrete mixtures containing various lengths and percentages of the fiber. The experimental design included the use of available aggregates, and polyester waste fibers as additives to enhance the properties of asphalt mixtures. Two fiber lengths of $1 \mathrm{~cm}$ and $2 \mathrm{~cm}$ were used with four different fiber contents of $0.2 \%, 0.35 \%, 0.50 \%$ and 0.65 by weight of total mixture. The results of the experimental work presented in this paper suggested that, in general, the addition of the polyester fibers was beneficial in improving both the stability and rutting resistance of the modified asphalt mixtures.
\end{abstract}

\section{Introduction}

As world population continues to increase, economic and industrial growth will continue to generate increasing amounts of waste materials. Disposal methods, whatever the form, have a direct impact on the delicate balance in the physical, chemical, and biological environments that constitute our global ecosystem [1, 2]. For many reasons, economical and environmental, the use of waste materials in construction as partial or full replacement of virgin materials has increased. Previous experience showed that the use of some waste materials such as polyester fiber has proven to be cost-effective, environmentally sound, and successful in improving some of the engineering properties of asphalt mixtures [3-6].

\footnotetext{
* Assoc. Prof., Dept. of Civil Engineering, Military Technical College, Cairo, Egypt.

** Ph.D. Candidate, Dept. of Civil Engineering, Military Technical College, Cairo, Egypt.

*** Prof., Dept. of Public Works, Faculty of Engineering, Cairo University, Giza, Egypt.

**** Prof., Dept. of Civil Engineering, Military Technical College, Cairo, Egypt.
} 
The textile industry, all over the world, generates millions of tons of fiber trim waste which goes into landfills every year. These fibers can provide asphalt mixtures with high stability and good rutting resistance. Several fabrics made from these fibers make excellent candidates for various Civil Engineering applications including pavement treatment and build ing. Cotton reinforcement with fiber mesh in asphalt concrete mixtures, in fiber forms was first attempted in 1934 [7] Also, metal wires were reused with the penetration of waster and asbestos was determined to be a health hazard by the Environmental Prote ction Agency (EPA) at that time. Another drawback of using fiber reinforcement was that fiberglass strands cut themselves at intersections within the mixture $[9,10]$. Another alternative to these materials have been provided by the textile industry with the development of synthetic materials such as polyester. These fibers provide the same benefits that the use of natural materials, however, for a longer period of time, without known risks to the environment and human health. Other previous studies suggested the benefit of the reinforcement of surface course pavements with polyester fiber [5, 11-13]. Research performed in Mexico and Texas has shown that the addition of polyester fibers in asphalt concrete pavements will reduce reflective cracking $[11,12]$.

Various primary factors should be taken into account while adding any waste product in asphalt pavement [1, 13]. Initially, the life cycle cost analysis must be performed to determine the effective of each material. A second consideration is the effect on quality and performance of the asphalt pavement. It would be poor economics indeed to incorporate waste that significantly increase the cost of the pavement and at the same time shortens the service life or increase the maintenance cost. The environmental advantages over its disposal in landfills are also considered in the use of waste materials. Over 60 years ago in USA, coarsely-woven cotton layers were spread between coats of asphalt to strengthen the road surface and comfort the ride $[14,15]$. The cotton served both as a binder for the asphalt cement and water-resistant cover to restrain water from seeping through cracks and damaging the road base.

Several fabric types (such as polypropylene, polyester, glass, nylon, or melded varieties of these and other fibers) have been used in pavements to reduce cracking. The major fabric materials currently used in pavements in the United States is polyester. During using, the fiber must be able to withstand temperatures up to $150^{\circ} \mathrm{C}$ and be suitably durable to sust ain traffic after the paving process $[8,16]$. Since a pavement moves in several directions under mechanical and thermal stress, the multi-directional physical properties of a non-woven polyester fiber seem to be better to the bi-axial properties of a woven material. In addition, the fiber should be lightweight, for ease in use, and highly resistance to chemicals, mildew, and fungus [13, 16, and 17].

The objective of this research was to determine whether homogeneously dispersed waste polyester fibers improve the Marshall stability and rutting resistance properties of the modified asphalt mixtures. In addition, the effect of various lengths and percentages of this fiber was investigated.

\section{MATERIALS AND METHOD OLOGY}

The materials and experimental design proce dure used in this study are as follows: 
The bitumen used was AC-60/70 bitumen. This asphalt was subjected to typical standard laboratory tests. The results of these tests are incorporated in Table (1). In this investigation, polyester waste in the fiber form of length $10 \mathrm{~mm}$ and $20 \mathrm{~mm}$ was used. Crushed Limestone was used as the aggregate material. Five aggregates were blended to the target gradation and the specific gravity of this aggregate blend was determined to be $2.625 \mathrm{~g} / \mathrm{cm}^{3}$. Some properties of the crushed limestone and specific gravities of aggregates are given in Table (2). The selected gradation and the specification limits are presented in Table (3). Table (4) shows Physical characteristics of polyester fibers. The Marshall Mix Design Method was used for designing the bituminous mixtures prepared with and without fibers. A speed adjustable vertical shaft mixer was used to mix the fiber and aggregate. The utilization strategy must be coupled with environmental and energy considerations to use available materials most efficiently. The aggregates used in hot mix asphalt (HMA) were prepared by mixing the fiber in $0.2 \%, 0.35 \%$, $0.50 \%$ and $0.65 \%$ (by the weight of total mixture) and AC-60/70. Aggregates with fiber and bitumen were heated separately to $165^{\circ} \mathrm{C}$ and $155^{\circ} \mathrm{C}$, respectively, and then they were mixed in a mechanical mixer. The mixture was placed in a Marshall mold and compacted by applying 75 blows on each side of the specimen at $145^{\circ} \mathrm{C}$. The standard dimensions of the samples were 63.5 $\mathrm{mm}$ height and $101.5 \mathrm{~mm}$ diameter. After having cooled at room temperature for one day and then conditioned in water at $60^{\circ} \mathrm{C}$ for $30-40 \mathrm{~min}$, the samples were tested with Marshall Test apparatus. All results are recorder as an average of the results of three test specimens. To investigate the effect of polyester fibers on the properties of HMA, A control mix (without fibers) was prepared and tested according to the testing program. The optimum asphalt content for the control mix was found to be $5.35 \%$ (by weight of total mix). Figure (1) illustrates a flow chart for the experimental program.

Table (1): Properties of the used binder.

\begin{tabular}{lc}
\hline $\mathrm{Pb}$ absorbed & $0.47 \%$ \\
Specific Gravity of Bitumen & 1.02 \\
Viscosity $(\min =320)$ & 364 \\
Softening point $\left(45-55^{\circ} \mathrm{C}\right)$ & 51 \\
Penetration, $25^{\circ} \mathrm{C}, 100 \mathrm{~g}, 5 \mathrm{sec}(1 / 10 \mathrm{~mm})$ & 63 \\
\hline
\end{tabular}

Table (2): Specific gravity, absorption, and (LOS) of aggregate .

\begin{tabular}{lccccc}
\hline Type / Properties & SEN-1 & SEN-2 & SEN-1" & Sand & Filer \\
\hline Bulk specific gravity $\left(\mathrm{gm} / \mathrm{cm}^{3}\right)$ & 2.55 & 2.54 & 2.54 & 2.458 & 2.066 \\
Saturated Surface Dry sp. & 2.60 & 2.59 & 2.60 & - & - \\
Gravity $\left(\mathrm{gm} / \mathrm{cm}^{3}\right)$ & & & & &
\end{tabular}


Apparent specific gravity $\left(\mathrm{gm} / \mathrm{cm}^{3}\right)$

Absorption (\%)

LOS Anglos (\%)

$\begin{array}{lllll}2.68 & 2.67 & 2.69 & 2.634 & 2.476\end{array}$

$\begin{array}{lllll}1.92 & 1.89 & 1.06 & 2.9 & 9.2\end{array}$

$19.56 \quad 9 \quad 20$

Table (3): Aggregate gradations and required specifications .

\begin{tabular}{cccc}
\hline \multirow{2}{*}{ Sieve \# } & Final & \multicolumn{2}{c}{ Specifications } \\
& Gradation & $\min$ & $\max$ \\
\hline 25 & 100.0 & 100 & 100 \\
19 & 99.4 & 80 & 100 \\
9.5 & 77.6 & 60 & 80 \\
4.75 & 54.2 & 48 & 65 \\
2.36 & 42.1 & 35 & 50 \\
0.6 & 23.9 & 19 & 36 \\
0.3 & 18.3 & 13 & 23 \\
0.15 & 11.1 & 7 & 15 \\
\hline
\end{tabular}

Table (4): Physical characteristics of polyester fibers

\begin{tabular}{lc}
\hline \multicolumn{1}{c}{ Test properties } & Typical values \\
\hline Specific gravity g/cm & \\
Weight, gm $/ \mathrm{m}^{2}$ & 1.35 \\
Tensile strength, daN $/ 5 \mathrm{~cm}$ & 68 \\
Elongation-at-break, $\%$ & 38 \\
Tear strength, $\mathrm{N}$ & 75.6 \\
Thermal sensitivity, ${ }^{\circ} \mathrm{C}$ & $-240^{\circ} \mathrm{C}$ (softens) \\
\hline Note: 1 daN (deca-Newton) $=10 \mathrm{~N}$.
\end{tabular}

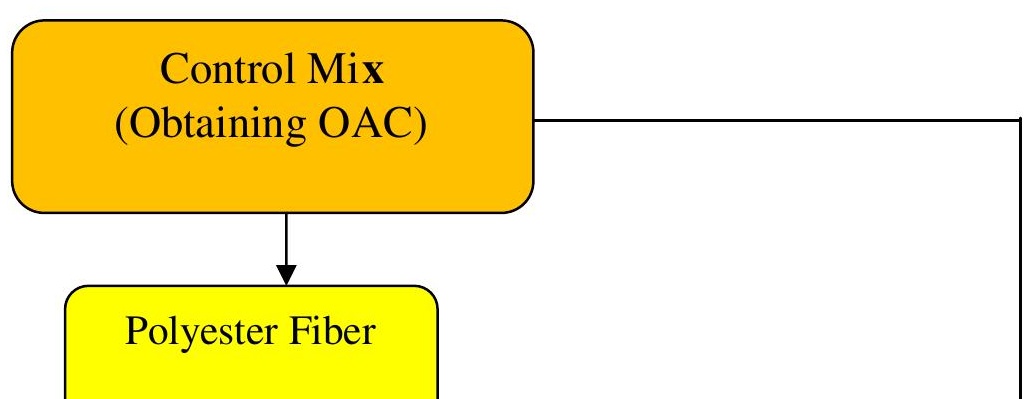


Figure (1): Flowchart of experimental program design

\section{RESULTS AND DISCUSSION}

\section{Stability}

Figure (2) illustrates the variation of stability of control mix with asphalt cont ent. Figure (3) shows the relation between Marshall stability and percent of polyester fibers for both fiber lengths of $1 \mathrm{~cm}$ and $2 \mathrm{~cm}$. Clearly, the value of Marshall stability is increased as the percent of polyester fibers increased until it reached a critical percentage (about 4.0\%). Beyond this percentage of fibers, any increase in fiber percent did not cause an increase in Marshall stability. Results of stability suggested that the change in stability is caused by the percent of adding fibers and the fiber length did not have a significant impact on stability values. The highest value of stability was resulted from using the fibers length of $2 \mathrm{~cm}$ and percentage $0.35 \%$ by the total weight of aggregate. Using polyester fibers of $10 \mathrm{~mm} / 20 \mathrm{~mm}$ length yielded higher stability values compared to the results of control mix. The percentage of increase was $27 \%$. 


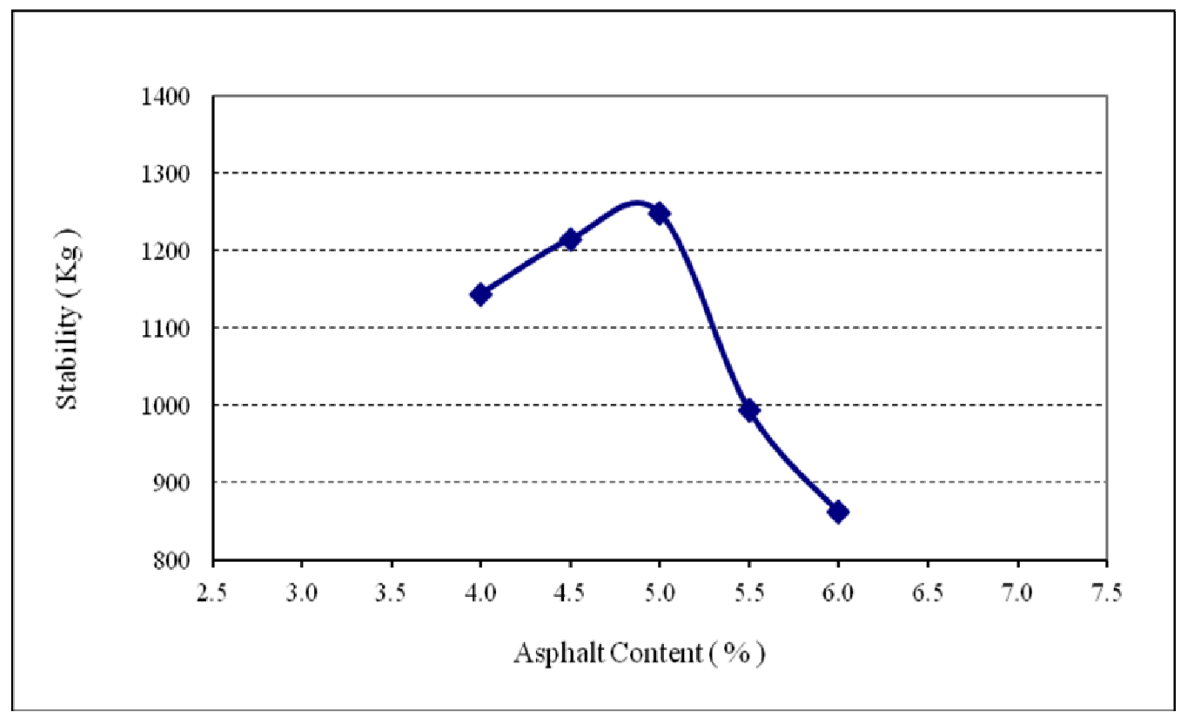

Figure (2): Stability versus asphalt content, control mix .

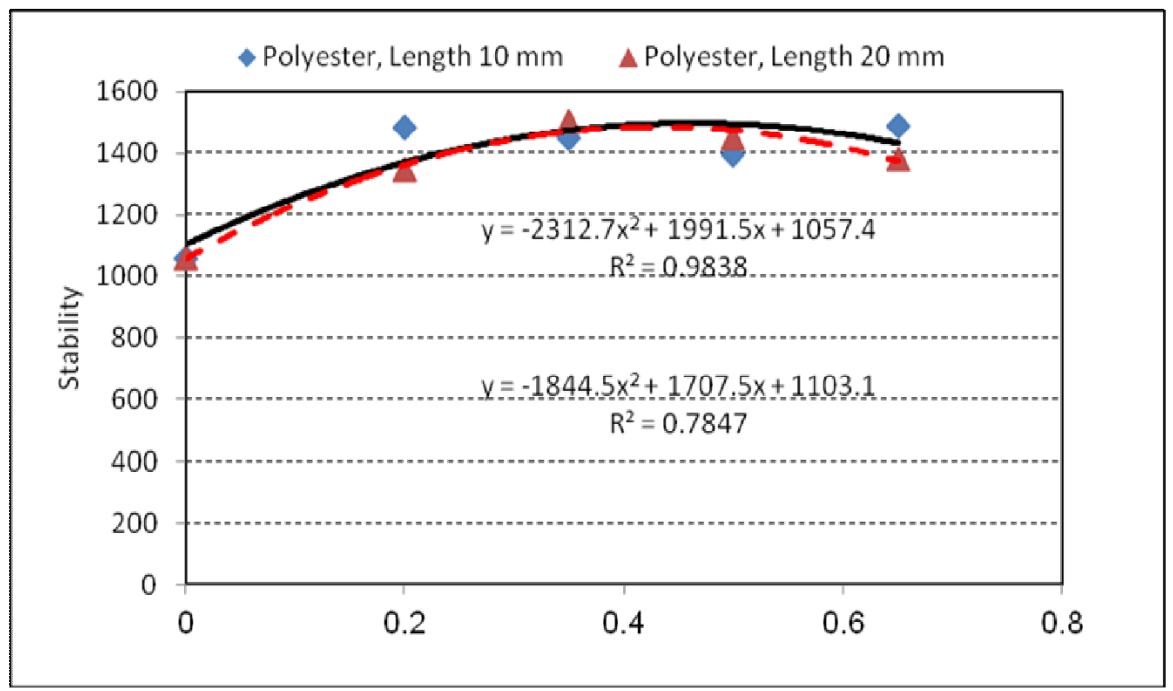

Figure (3): Stability versus polyester fibers content .

\section{Bulk density}

Figure (4) shows that the unit weight for the fiber reinforced mixture seemed to slightly decrease as the percentage of fibers added increased. The slope of less than 0.1 emphasizes that adding polyester fibers to HMA did not cause bulk density to change. The results showed that length of the fibers had no significant effect on the bulk density of the mixture. Bulk density value of control mix (at $0.0 \%$ fiber content) is found to be $2.383 \mathrm{~g} / \mathrm{cm}^{3}$. 


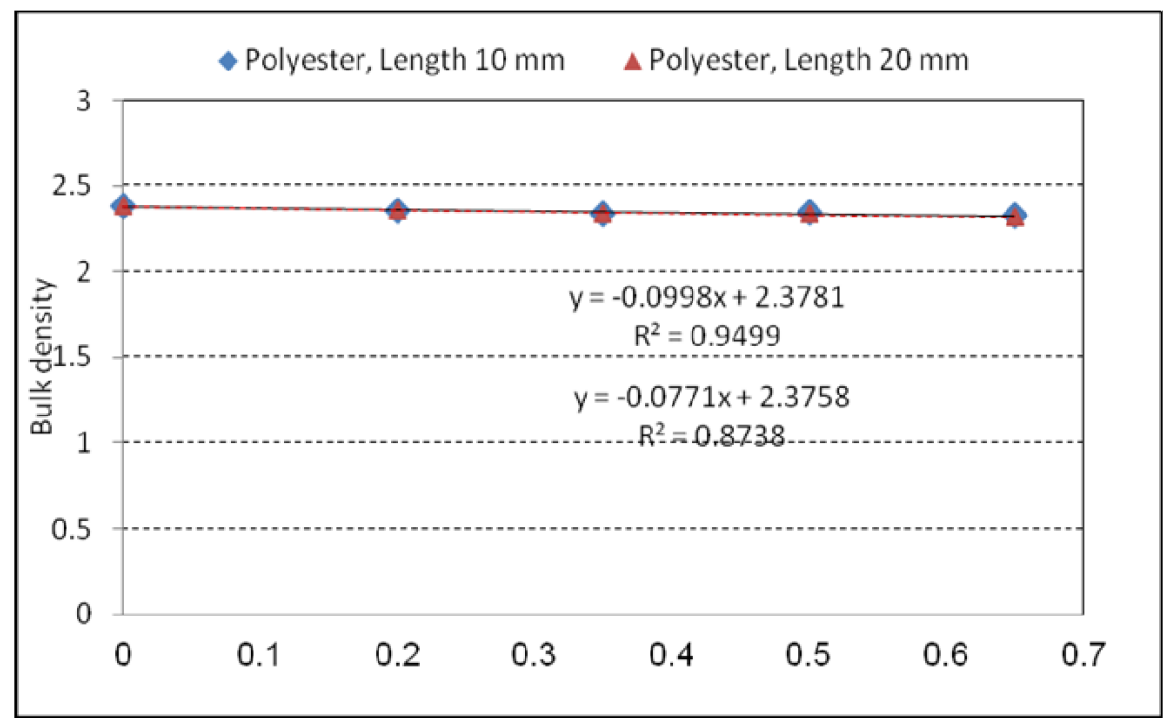

Figure (4): Density versus polyester fibers content.

\section{Flow}

The results of flow are presented in Figure (5) for both control mix (0.0\% fiber content) and other mixes using polyester fibers. Flow value of control mix is found to be 14.7 (0.01in). The flow values increased with the increase of fiber content. The rate of increase is smaller for fiber length of $1 \mathrm{~cm}$. for most cases, fiber length of $1 \mathrm{~cm}$ yielded flow values less than $16(1 / 100 \mathrm{in}$.). When fiber length of $2 \mathrm{~cm}$ length was used, most of the flow values exceeded 16 (1/100 in.). For fiber content up to $0.35 \%$, same value of flow was resulted in for both fiber length of $1 \mathrm{~cm}$ and $2 \mathrm{~cm}$. The results showed that flow values were significantly higher for $2 \mathrm{~cm}$ length by $0.65 \%$ fibers than the flow of control specimens.

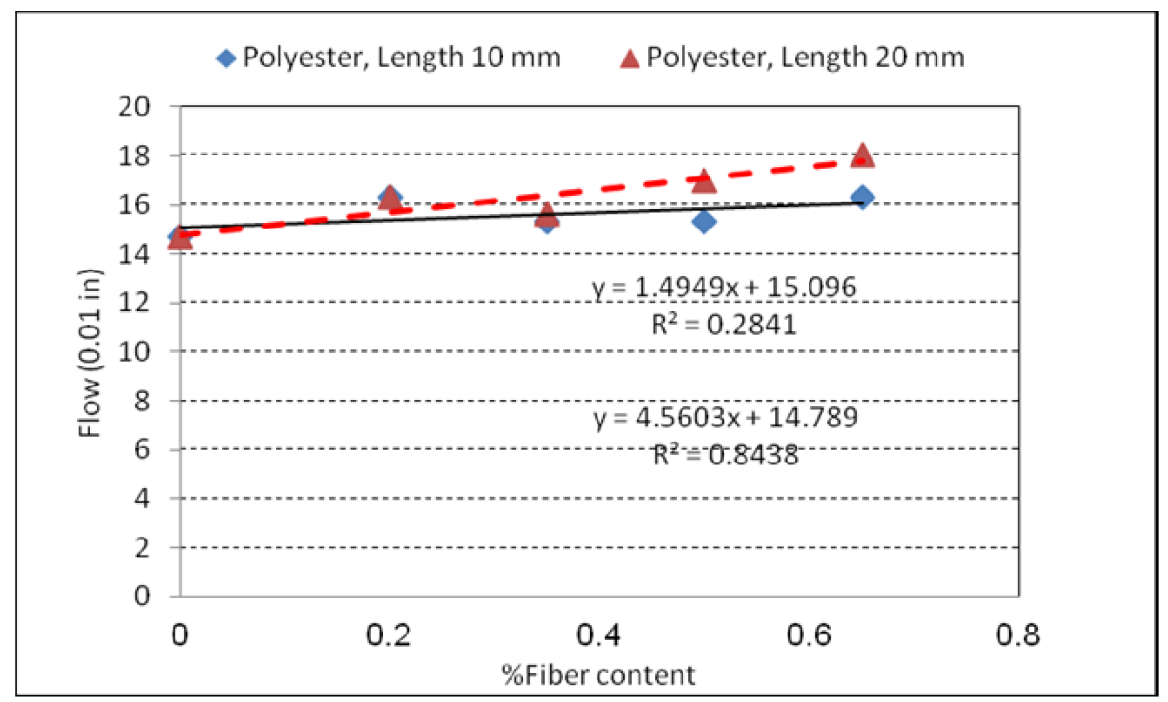


Figure (5): Flow versus polyester fibers content.

\section{Air voids}

Figure (6) shows that the specimens containing no fibers had lower air void s than the specimens containing polyester fibers. Air voids value of control mix $(0.0 \%$ fibers $)$ is found to be $4.55 \%$. Increasing the fibers content caused air void values to increase. Same trend as that of flow is noticed where $1 \mathrm{~cm}$ fiber length resulted in lower values of air voids compared to fiber length of $2 \mathrm{~cm}$. knowing that air voids should be $3-5 \%$ (ASTM D 1559) it is recommended to use the fiber length of $1 \mathrm{~cm}$ if fiber content exceeds $0.35 \%$.

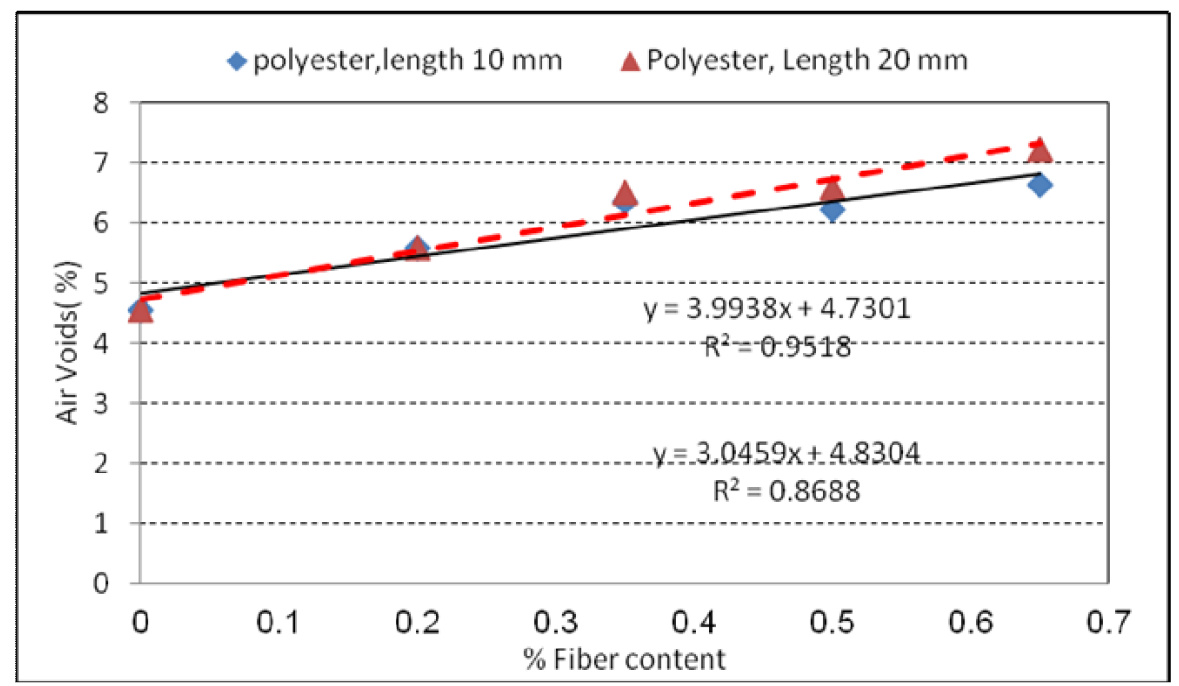

Figure (6): Air voids versus polyester fibers content.

\section{Rutting test}

Three specimens of control mix in addition to three specimens containing $0.35 \%$ fibers of $1 \mathrm{~cm}$ length were prepared for rutting test using wheel tracker machine. The wheel tracker machine is equipped by a temperature control cha mber to maintain the test at $60^{\circ} \mathrm{C}$. The test was conducted for 45 minute. Figure (7) shows the results of rutting test where rut depth was plotted against time of the test. The figure illustrates that the specimens containing no fibers had lower rutting resistance. At the end of the test, using polyester fibers could decrease the rut depth by $40 \%$. 


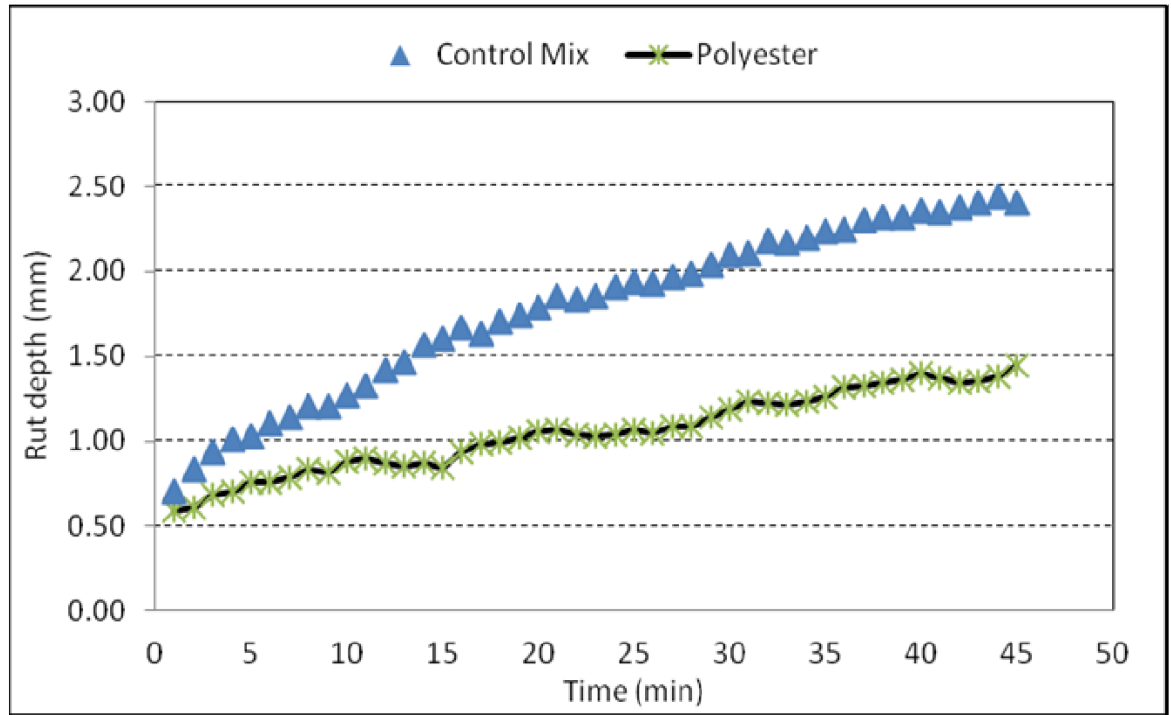

Figure (7): Benefit of using polyester fibers to reduce rut depth of HMA.

\section{CONCLUSIONS}

Based on the results of this study, polyester fibers could be used efficiently to enhance rutting resistance of HMA. At the same time, polyester fibers resulted in a significant increase in Marshall Stability. These conclusions are supported by:

- The specimens prepared with $0.35 \%$ fibers (of length $1 \mathrm{~cm} / 2 \mathrm{~cm}$ ) could improve stability by $27 \%$. At the same time, it did not increase flow significantly (flow values $<161 / 100$ in).

- The specimens prepared with $0.35 \%$ fibers of $1 \mathrm{~cm}$ length yielded lower rut depth compared to the control mix. Polyester fibers decreased the rut depth by $40 \%$ at the end of the test.

\section{REFERENCES}

[1] Freeman R.B, Burati J.L, Amirkhanian SN, and Bridges WC., "Polyester Fibers in Asphalt Paving Mixtures", Assoc Asphalt Paving Technol 1989; 58:387-409.

[2] Boustead I., "Eco-Profiles of the European Polymer Industry", Report 3. Polythene and Polypropylene, Association of Plastics Manufacturers in Europe; 1993.

[3] Kandhal P.S, "Recycling of Asphalt pavement - An Overview", In: Proceedings of Association of Asphalt Paving Technologists, vol. 66; 1997.

[4] Foo K.Y, Hanson D.I, and Lynn T.A, "Evaluation of Roofing Shingles in Hot Mixture Asphalt", J. Mater. Civil Eng., 1999; 11:15-20.

[5] Shen J.N, Amirkhanian S.N, and Xiao F.P, "Characterization of Aging of Recycled CRM Binders Containing Rejuvenating Agents", Washington (DC): Transportation Research Board, No. 1962; 2006. p. 21-7. 
[6] Xiao F.P, Amirkhanian S.N, and Juang C.H, "Rutting Resistance of Rubberized Asphalt Concrete Pavements Containing Reclaimed Asphalt Pavement Mixtures", J. Mater. Civil Eng., 2007; 19:475-83.

[7] Maurer D.A and Janice L.A, "Polyester Fiber-Reinforced ID-2 Wearing Course: Construction and Early Performance Report", Pennsylvania Department of Transportation, Research Project 657-7; 1987, p. 84-106.

[8] Smith G.G and Barker R.H, "Life Cycle Analysis of a Polyester Garment", Resour. Conserv. Recycling, 1995; 14:233-49.

[9] Tons W.E and Egons D.J, "Five-Year Performance of Welded Wire Fabric in Bituminous Resurfacing", Highways Research Board Bulletin; 1961 [\# 290].

[10] Alter H, "The Origins of Municipal Solid Waste: II. Policy Options for Plastics Waste Management", Waste Manage Res., 1993; 319-32.

[11] Button J.W and Thomas G.H, "Synthetic Fibers in Asphalt Paving Mixtures", Texas State Department of Highways and Public Transportation, Research Report 319-IF; 1984.

[12] Maurer D.A, "Comparison of Methods to Retard Reflective Cracking in Bituminous Concrete Pavements using Fabrics and Fibers: Construction and Early Performance Report", Pennsylvania Department of Transportation, Research Project No. 83-8; 1985.

[13] Waller H.F, "Use of Waste Materials in Hot-Mix Asphalt", ASTM Publication No. 04011930-08; 1992. p. 16-98.

[14] George B.S, "Evaluation of the Phillips Petroleum company's Product Petromat. Unpublished report; 1976.

[15] Putman B.J and Amirkhanian S.N, "Utilization of Waster Fibers in Stone Matrix Mixtures", Resour. Conserv. Recycling, 2004; 42:265-75.

[16] Gaw W.J, "The Measurement and Prediction of Asphalt Stiffness at Low and Intermediate Pavement Temperature", AAPT 1978; 47:457-94.

[17] Rebeiz K.S, Fowler D.W, and Paul D.R, "Formulating and Evaluating an Unsaturated Polyester Composite Made with Recycled PET, J. Mater. Educat. 1991; 13:441- 54. 
Proceedings of the $\mathbf{9}^{\text {th }}$ ICCAE-9 Conference, 29-31 May, 2012 
Proceedings of the $\mathbf{9}^{\text {th }}$ ICCAE-9 Conference, 29-31 May, 2012 